\title{
Gaziantep-Kahramanmaraş Bölgesinde Meydana Gelen Deprem ve Taş Ocağı Patlatmalarının Zaman ve Frekans Ortamı Yöntemleri ile Sinıflandırılması
}

\author{
Evrim YAVUZ*, Fadime SERTÇELİK, Hamdullah LIVAOĞLU, T. Serkan IRMAK
}

Kocaeli Üniversitesi, Jeofizik Mühendisliği Bölümü, Kocaeli

(ORCID: 0000-0002-9175-8962) (ORCID: 0000-0002-4549-7941)

(ORCID: 0000-0002-7947-4107) (ORCID: 0000-0002-4504-6286)

\begin{abstract}
$\ddot{\mathbf{O z}}$
Gaziantep-Kahramanmaraş bölgesi, Türkiye'nin güneydoğusunda tektonik yönden aktif bir alanda yer almaktadır. Bölgede, maden ve taş ocakları yaygın bir şekilde bulunmaktadır. Bunlara ait işletmelerde malzeme temini için patlayıcılar kullanılmaktadır. Dolayısıyla bölgede sadece tektonik olaylar değil yapay kaynaklı patlatmalar da sismik istasyonlar tarafından kayıt edilebilmektedir. Yapay ve doğal kaynaklı sarsıntı kayıtlarının sismik kataloglarda meydana getirdiği karmaşıklık, sismoloji çalışmaları için büyük sorun teşkil etmektedir. Bu çalışmanın amacı, inceleme bölgesindeki doğal ve yapay kaynaklı olayların ayırt edilerek kataloglardaki tanımlamanın net olarak ortaya konulmasıdır. Bu çalışmada, Boğaziçi Üniversitesi Kandilli Rasathanesi Deprem Araştırma Enstitüsü Bölgesel Deprem-Tsunami İzleme Merkezi (KRDAE-BDTIMM) tarafından işletilen GAZ sismik istasyonunun kayıtları kullanılmıştır. Lokal büyüklüğü en fazla 3.0 olan ve Ocak 2013-Nisan 2016 yılları arasında meydana gelen 95 adet sismik olay kayıtlarının sadece yatay bileşenleri kullanılmıştır. Genlik oranı, karmaşıklık ve Sürekli Dalgacık Dönüşümü (SDD) yöntemleri ile analizler yapılmıştır. Sınıflandırmada istatistiksel yaklaşım olarak lineer ve karesel ayrımlaştırma fonksiyonları (LAF-KAF) kullanılmıştır. Genlik oranı yöntemine göre, LAF ile 69 adet ve KAF ile 70 adet deprem ayrımlaştırılmıştır. Karmaşıklık yöntemine göre ise 24 patlatma kaydı yine aynı fonksiyonlar ile kategorize edilmiştir. Sürekli Dalgacık Dönüşümü analizine göre ise tüm olaylar \%100 başarı ile sınıflandırılmıştır. Sonuçlar, ilk gözlem ile kıyaslandığında KAF'ın LAF'a ve genlik oranı yönteminin karmaşılılk yöntemine göre daha iyi bir sınıflandırma sunduğu ve SDD'nin ise diğer yöntemlere göre daha başarılı ayrımlaştırma yaptığı şeklinde yorumlanmıştır. Ayrıca, Sürekli Dalgacık Dönüşümü analizi ile de olaylar \%100 başarı ile sınıflandırılmıştır.
\end{abstract}

Anahtar kelimeler: Ayrımlaştırma, deprem, istatistiksel yaklaşımlar, Sürekli Dalgacık Dönüşümü, taş ocağı patlatmasi.

\section{Classification of Quarry Blasts and Tectonic Events with Time and Frequency Domain Methods in Gaziantep-Kahramanmaras Region, Turkey}

\begin{abstract}
Gaziantep-Kahramanmaras region is located on the tectonically active area and the southeastern part of Turkey. In this region, mining and quarry companies are widely scattered and the explosives are being used for material supply. Therefore, not only the tectonic events but also the artificial explosions could have been recorded by the seismic stations in the region. The complexity of the catalogues through the recordings of artificial and natural seismic events is a major problem for the seismological studies. The aim of this study is to distinguish between natural and artificial sources in the investigated area and to provide a clear definition in catalogs. The recorded signals were provided from the earthquake station GAZ, operating by Bogazici University Kandilli Observatory and Earthquake Research Institute Regional Earthquake-Tsunami Monitoring Center (KOERI-RETMC). Only the vertical components of the seismograms of 95 seismic events with up to 3.0 local magnitude in between January 2013-April 2016 were used. The analyses were done with amplitude ratio, complexity and Continuous Wavelet
\end{abstract}

*Sorumlu yazar: evrim.yavuz@kocaeli.edu.tr

Geliş Tarihi: 12.12.2018, Kabul Tarihi: 07.05.2019 
Transform (CWT) methods. The statistical approaches that the linear and quadratic discriminant functions (LDFQDF) were used for classification of the events. About an amplitude ratio method, 69 and 70 earthquakes were determined with LDF and QDF, respectively. On the complexity method, 24 quarry blasts were discriminated with the same functions. According to the Continuous Wavelet Transform analysis, all events were categorized with the accuracy of $100 \%$. As the results, QDF could classify the events better than LDF and these functions are more successful in the amplitude ratio method rather than complexity through the comparison with first visual inspection, also CWT is able to classify more successfully than other methods. In addition, all events were discriminated through the Continuous Wavelet Transform analysis with a success rate as $100 \%$.

Keywords: Discrimination, earthquake, statistical approaches, Continuous Wavelet Transform, quarry blast.

\section{Giriş}

Gaziantep ve Kahramanmaraş illeri arasında kalan çalışma alanı, sol yanal doğrultu atımlı Doğu Anadolu Fay Zonu'na ve Bitlis-Zagros Bindirme Zonu'na yakın bir bölgedir. Tektonik karmaşanın içerisinde kalan bu bölgede, doğal kaynaklı olaylara sıkça rastlanmaktadır. Ayrıca taş, kaya, mıcır gibi malzeme ihtiyacından dolayı bölge içerisinde kurulan taş ocağı işletmelerinde malzemeyi koparabilmek amaciyla dinamit, ANFO, vb. patlayıcılar kullanmaktadır. Bunun sonucunda ise yapay kaynaklı bu sarsıntılar deprem kayıt istasyonlarında da kaydedilebilmektedir. Mikro-ölçekli bu sarsıntılar bölgede olan küçük depremler ile birlikte sismik kataloglarda karmaşıklıklara neden olabilmektedirler. Farklı kaynak yapılarına sahip olayların birbirinden ayrımlaştırılarak kataloglanması işlemi, depremsellik gibi çalışmalar üzerinde büyük öneme sahiptir. Aksi takdirde bu veriler, bölgede yapılabilecek detaylı sismolojik çalışmalar için yanlış yönlendirme teşkil edebilmektedirler.

Doğal ve yapay kaynaklı sarsıntıları birbirinden ayırt edebilmek için geçmişten günümüze çeşitli yöntemler tercih edilmiştir. Su ve arkadaşları [1] ilk olarak koda dalgalarını kullanmış ve sinyallerin güç yoğunluğu hesabı ile ayrımlaştırma yapmıştır. Aki [2] ise lokal uzaklıklardaki koda dalgalarını kullanarak doğal-yapay sarsıntı ayrımını uygulamıştır. Güney Rusya'da $\mathrm{Pg} / \mathrm{Lg}$ büyüklük oranı hesaplanarak bir ayrımlaştırma çalışması gerçekleştirilmiştir [3]. İsrail'in sahip olduğu yoğun sismik ağ kullanılarak Orta Doğu için doğal ve yapay kaynaklı sarsıntı ayrımı genlik oranı yöntemi ile yapılmıştır [4]. P ve S dalgalarının yer değiştirme spektrumlarından köşe frekansı tespiti yapılıp patlatmalar depremlerden ayrımlaştırılmıştır [5]. Ayrıca yapay sinir ağları kullanılarak taş ocağı patlatmalarının sınıflandırma analizi gerçekleştirilmiştir [6]. Armutlu Yarımadası ve yakın civarı için yapılan ayrımlaştırma analizinde beş ayrı metot kullanılmış ve bunların kendi aralarındaki başarı oranı kıyaslanmışırı [7]. Genel olarak P ve S dalgalarının en büyük genliklerinin oranı (genlik oranı yöntemi), karmaşıklık analizi ile birlikte bazı istatistiksel yaklaşımlar kullanılarak ve Sürekli Dalgacık Dönüşümü ile ayrımlaştırma analizleri yapılmaktadır [8-21].

Çalışma sahasında daha önce doğal-yapay sarsıntı ayrımlaştırma çalışması yapılmamıştır. Böyle bir çalışmanın eksikliği sismik kataloglarda karmaşıklığa ve böylece yapılacak sismolojik çalışmalarda yanlış yorumlamalara neden olacaktır. Bu çalışmada, Gaziantep-Kahramanmaraş bölgesi civarında gerçekleşmiş olan olayların kaynak tipleri genlik oranı, karmaşıklık ve Sürekli Dalgacık Dönüşümü analizleri kullanılarak belirlenmeye çalışılmıştır. Lineer ve karesel ayrımlaştırma fonksiyonları yardımı ile de iki ayrı tipte meydana gelen sarsıntıların sınıflandırılması amaçlanmıştır. Elde edilen sonuçların sismik kataloglardaki patlatma kayıtlarını ayırmada, depremsellik analizlerinde ve buna benzer sismolojik çalışmalarda yardımcı olabileceği düşünülmektedir. Bu çalışmanın bir kısmı IMASCON2018'de sözlü olarak sunulmuştur.

\section{Bölgenin Aktif Tektoniği}

Bölge, Arap Levhası'nın kuzeye doğru hareketiyle Anadolu Lehvası'nı sıkıştırması sonucu oluşan tektonik karmaşanın etkisindedir. Bu karmaşanın en büyük oluşumu ise sol yanal doğrultu atımlı Doğu Anadolu Fay Zonu ile birlikte Bitlis-Zagros Bindirme Zonu'dur [22-23] (Şekil 1). Ayrıca bu karmaşadan dolayı da bölge içerisinde irili ufaklı lokal fayların hakimiyeti de göz önündedir. Böylece bölgedeki depremlerin yaratacağı önemli etki çok önemlidir. 
Bölgenin genel jeolojisine; Eosen ve Miyosen yaşlı kireç taşlarının, Mesozoyik yaşlı ultrabazik kayaların ve Üst Miyosen yaşlı bazaltların hakim olduğu gözükmektedir [24]. Ayrıca bölge; Sakçagöz, Narl, Amanos ve Pazarcık Segmetleri çevresinde bulunmaktadır [25].

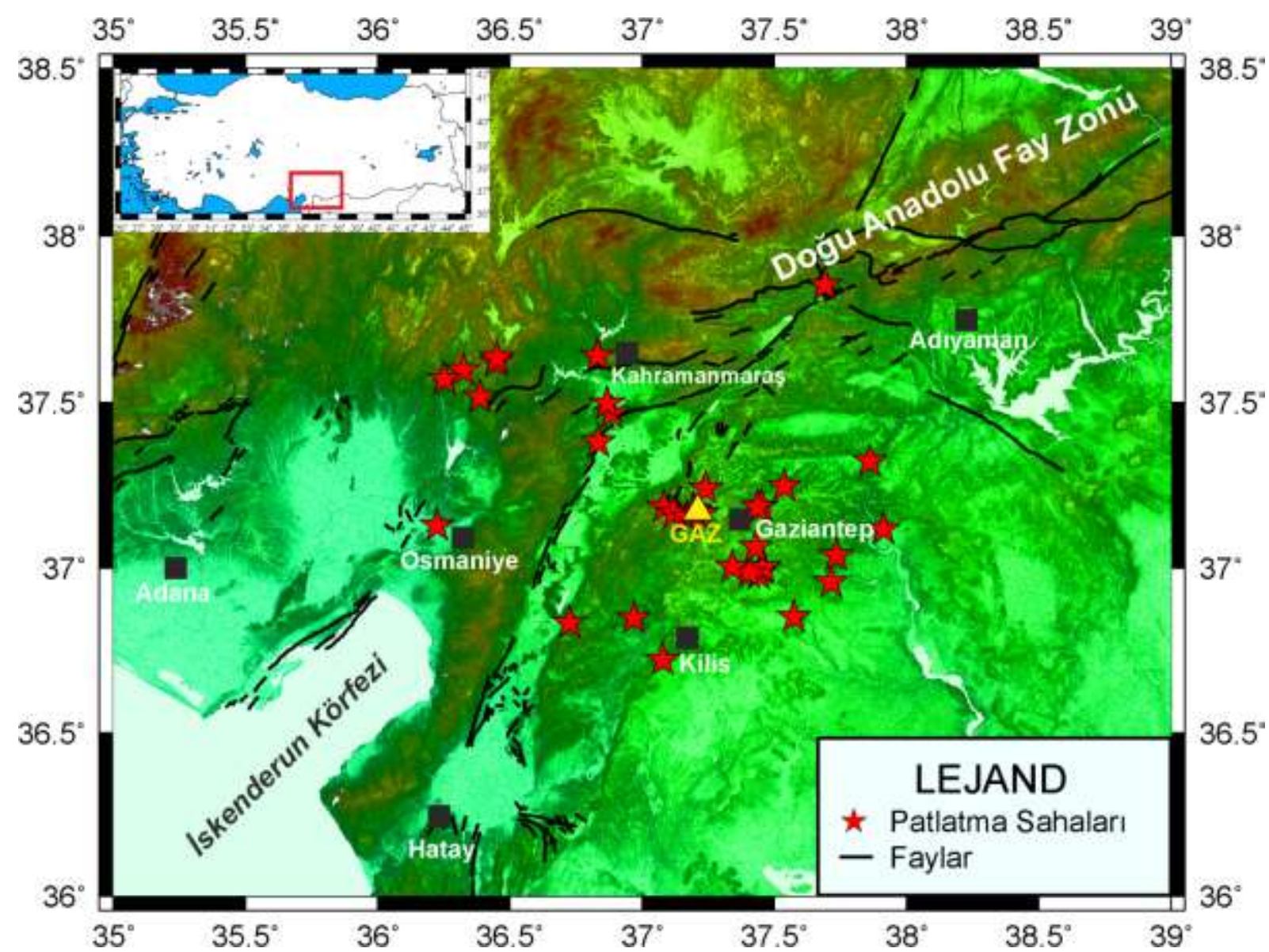

Şekil 1. Bölgenin aktif tektoniği ve sadece çalışma bölgesi çevresindeki mevcut patlatma sahaları. Sarı üçgen ile GAZ deprem istasyonu gösterilmiştir. Faylar, [25]'e dayanılarak çizdirilmiştir.

\section{Veri Özellikleri}

Doğal ve yapay sarsıntıların sınıflandırılması amacıyla Boğaziçi Üniversitesi Kandilli Rasathanesi Deprem Araştırma Enstitüsü (KRDAE) Bölgesel Deprem-Tsunami İzleme Merkezi (BDTİM) tarafından işletilen GAZ sismik istasyonu kullanılmıştır. Bu istasyon hem bölgede meydana gelen sismik olaylara yakın (en fazla $25 \mathrm{~km}$ ) hem de sinyal/gürültü oranı yüksek kayıtlara sahiptir. Üç bileşeni bulunan sahip bu hız kayıtçısının sadece düşey bileşeni $(Z)$ ayrımlaştırma analizi için kullanılmıştır. Ocak 2013 ile Nisan 2016 yılları arasında meydana gelmiş lokal büyüklügüu $\left(\mathrm{M}_{\mathrm{L}}\right)$ 3.0'dan daha küçük olan 95 adet veri analiz edilmiştir. Özel durumlar hariç patlatmaların göl, nehir ve deniz gibi su içeriğine sahip bölgelerde oluşmadığı bilindiği için, sadece kara sınırları içerisinde yer alan olaylar kullanılmıştır. Ayrıca yasalar gereği taş ocağı patlatmalarının gece yapılmayacağından dolayı GMT saat diliminde 06:00 ile 17:00 arasında meydana gelen olaylar tercih edilmiştir. Bölge içerisinde bu uzun süre zarfinda çok daha fazla olay olmasına rağmen bazı sismik kayıtlar GAZ istasyonunda meydana gelen teknik problemlerden (enerji kaybı, kayıt edilemeyen sinyal, gürültülü kayıt, vb.) dolayı bu çalışmada kullanılamamıştır.

\section{Yöntem}

Bu çalışmada, üç farklı yöntem ile birlikte iki farklı istatistiksel yaklaşım GAZ istasyonunun 95 adet sismik kaydına uygulanmıştır. Patlatma kayıtlarında $\mathrm{P}$ dalgası ilk hareket yönünün yukarı yönlü olması, $S$ dalgasının genliğinin düşük olması, $P$ dalgası genliğinin yüksek olması ve Rg fazının gözlemlenmesi 
gibi durumlara göre analizin ilk aşamasında göz ile tespit yapılmıştır (Şekil 2). Bu gözlemsel tespitin amacı, istatistiksel olarak ayrım yapılabilmesi için ilk girdi verisinin tanımlanmasından dolayıdır. Burada, genlik ve karmaşıklı yöntemi ile elde edilen sonuçlar, ilk gözlemsel tespit ile kıyaslanıp birbirleri arasındaki hata oranını vermektedir.
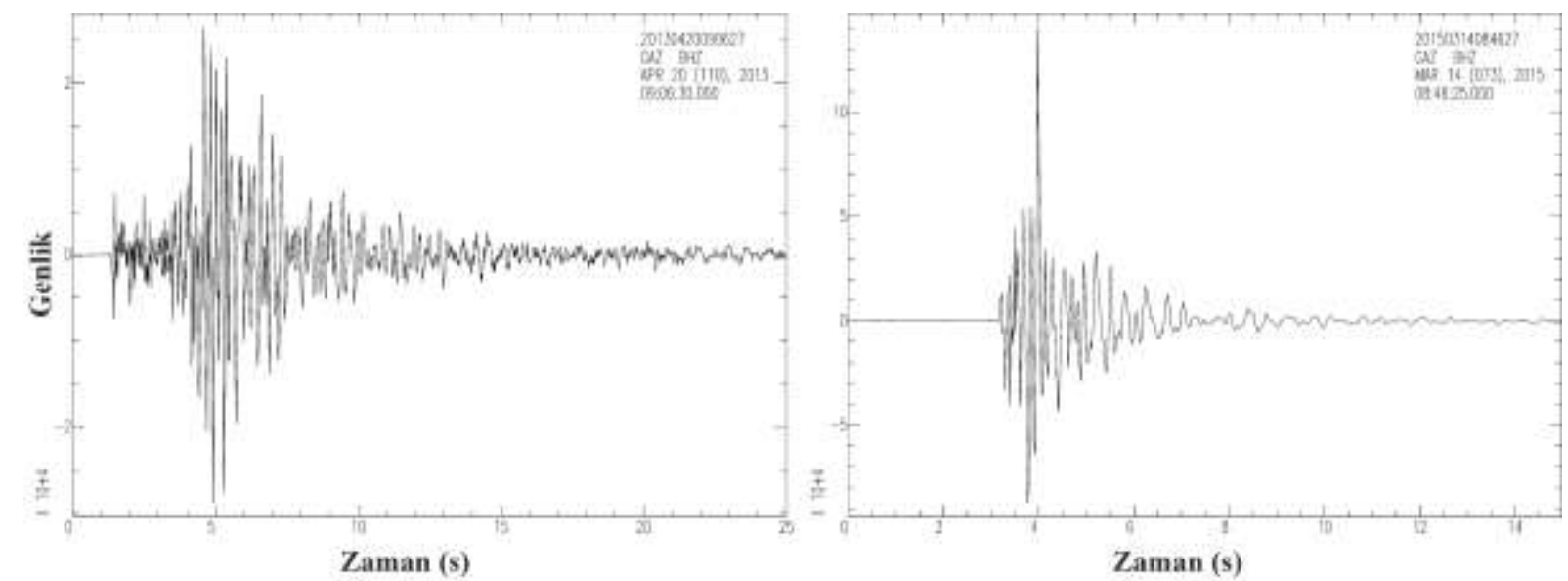

Şekil 2. Sol tarafta 20.04.2013 tarihli 09:06:27 (GMT) saatli bir deprem kaydının GAZ istasyonunun düşey bileşen sismogramı. Sağ tarafta 14.03.2015 tarihli 08:46:27 (GMT) saatli bir patlatma kaydının GAZ istasyonunun düşey bileșen sismogramı.

\subsection{Genlik oranı yöntemi}

$\mathrm{Bu}$ yöntem, düşey bileşende gözlenen en yüksek $\mathrm{P}$ ve $\mathrm{S}$ dalgası genliklerin birbirlerine oranını ve buna karş11ık en yüksek genlikli S dalgasının logaritmasını karşılaştırmaktadır [8-9]. Genelde, depremlerde S dalgası genliği P dalgasına nazaran daha yüksek gözlemlenirken yapay kaynaklı olaylarda bu durum tam tersine dönmektedir. Yöntem, zaman ortamında kayıt edilen verilere uygulandığı için herhangi bir ortam dönüşümü yapılmaz. Ayrıca sadece genlik okumalarına ihtiyaç duyulduğu için de analizi basit bir yöntem olarak literatürde yerini almıştır. Çabuk ve uygulanması kolay olduğundan dolayı da doğalyapay olay ayrımlaştırma çalışmalarında yaygınca kullanılmaktadır.

\subsection{Karmaşıklık yöntemi}

Bu yöntemde ilk olarak sismogram iki ayrı pencereye ayrılmaktadır $\left(t_{0} t_{1}, t_{1} t_{2}\right)$. Bu pencereler arasında kalmış sinyallerin güçleri $\mathrm{s}^{2}(t)$ hesaplanmaktadır. İki ayrı pencerenin de oranı alınarak bulunan bu değere, karmaşıklık (C) adı verilir (Denklem 1). Sonrasında ise yüksek ve alçak olmak üzere iki ayrı frekans bandında $\left(h_{1}-h_{2}, l_{1}-l_{2}\right)$ veriye filtre işlemi uygulanarak sinyalin spektral genliği a $(f)$ hesaplanır. İki ayrı filtrenin spektral genlikleri birbirine oranlanır ve elde edilen bu değere de spektral oran (Sr) adı verilir (Denklem 2) [10-11].

$$
\begin{aligned}
& C=\int_{t_{1}}^{t_{2}} s^{2}(t) d t / \int_{t_{0}}^{t_{1}} s^{2}(t) d t \\
& S r=\int_{h_{1}}^{h_{2}} a(f) d f / \int_{l_{1}}^{l_{2}} a(f) d f
\end{aligned}
$$

\subsection{Sürekli Dalgacık Dönüşümü (SDD) yöntemi}

Sürekli Dalgacık Dönüşümü, Kısa Zamanlı Fourier Dönüşümü, Haar Dönüşümü, Ayrık Dalgacık Dönüşümü, Daubechies Dönüşümü gibi frekans ortamında yapılan bu dönüşümler zaman ortamında kaydedilen sinyallerin zaman ve frekans ortamındaki genlik değerlerini vermektedir. Sürekli Dalgacık Dönüşümü (SDD) de zaman ve frekansın iki boyutlu bir fonksiyon olarak eşleniğini gösterir. $\mathrm{Bu}$ çalışmada kullanılan SDD yöntemi, jeofizik çalışmalarda sismik dalgaların nitelendirilmesinin yanı sıra kaynaktaki enerji karakteristiğinin belirlenmesinde ve deprem patlatma ayrım analizlerinde de kullanılmaktadır [26]. [12] sismik dalgaların türlerine ayrılmasında dalgacık dönüşümünü kullanmıştır. 
Depremlerdeki sismik dalgalar daha uzun bir zaman penceresinde farklı frekanslara ve genliklere sahipken, patlatmalarda ise bu zaman aralığının daha dar olduğu çalışmalarda gözlemlenmiştir [16-2021-27]. SDD yöntemi Denklem 3'te gösterilmiştir.

$S D D(\alpha, \tau)=\frac{1}{\sqrt{|\alpha|}} \int_{-\infty}^{+\infty} f(t) \cdot \delta\left(\frac{t-\tau}{\alpha}\right) d t$

Burada $\delta((\mathrm{t}-\tau) / \alpha)$, fonksiyonu dalgacık veya çekirdek dalgacığı olarak adlandırılır. Fonksiyonun zaman ekseni boyunca kaymasını sağlayan " $\tau$ " etmeninin yanı sıra farklı olarak fonksiyonu ölçekleyen bir " $\alpha$ " etmenini de kapsamaktadır. Bunlardan $\tau$, kaydırma etmeni; $\alpha$ ise ölçekleme etmeni olarak adlandırılır. Dalgacık, her $\tau$ ve $\alpha$ değeri için bilimsel olarak aynı, ancak $\alpha$ etmenine bağlı olarak farklı ölçülededir [26]. Örneğin; [12] sismik dalgaların türlerine ayrılmasında Morlet dalgacı̆̆ı kullanmıştır (Denklem 4).

$M(f)=\frac{1}{\pi^{1 / 4}} e^{-w_{0}^{2}\left(\frac{f}{f_{i}}-1\right)^{2} m}$

Denklemde, $m$ dalgacık parametresi olarak adlandırılır ve zaman-frekans çözünürlülükleri arasındaki değişimi kontrol eder. Örneğin $m$ değerinin artması daha iyi frekans çözünürlülüğü sağlarken zaman çözünürlülüğünü azaltır. $f_{\mathrm{i}}$ ise dalgacığın merkez frekansını temsil eder. Çalışmada $m$ değeri 10 , merkez frekansı da $1 \mathrm{~Hz}$ olarak hesaplamalar yapılmıştır. Ayrıca $w_{\mathrm{o}}$ değeri olarak 6 seçilmiştir. Sismik kayıtların, frekans ortamında Morlet dalgacığı ile çarpılarak elde edilen 2-boyutlu zaman-frekans haritaları sayesinde enerji dağılımları genliklerin değişimleri olarak incelenmiştir. Böylece zamanın bir fonksiyonu olarak elde edilen baskın frekans bandındaki değişimler ile deprem ve patlatma ayırım analizleri yapılmıştır.

\section{4. İstatistiksel yaklaşımlar}

Ayrımlaştırma analizi, farklı normal (Gaussian) dağılımlar ile oluşturulmuş farklı gruplardaki verilerin sınıflandırılması için yapılmaktadır. Bir sınıflandırıcı oluşturabilmek için, ayrımlaştırma fonksiyonu her bir gruba ait normal dağılımın parametrelerine yaklaşım yapmaktadır. Ayrımlaştırma fonksiyonları, en küçük sınıflandırma hatası neticesinde ilk olarak girilen veri gruplarının sonrasında yeni veri sınıflarına ait bir sınıflandırma yapmaktadır. Bu çalışmada, hem genlik oranı hem de karmaşıklık yöntemleri bulgularına, lineer ve karesel ayrımlaştırma fonksiyonları ile sınıflandırma uygulanmıştır [28-29-30]. Lineer ayrımlaştırma fonksiyonu (LAF) (Denklem 5) tüm gruplara ait tek kovaryans matrisi sağlarken, karesel ayrımlaştırma fonksiyonu (KAF) (Denklem 6) ise aynı kovaryans matrisini her bir gruba sağlamaktadır.

$$
\begin{aligned}
& \boldsymbol{F}_{\mathbf{L A F}}=\boldsymbol{K}+\boldsymbol{L}(\mathbf{1}) * \boldsymbol{x}+\boldsymbol{L}(\mathbf{2}) * \boldsymbol{y} \\
& F_{K A F}=K 1+\left[\begin{array}{ll}
x & y
\end{array}\right] * L 1+\sum\left\{\left(\left[\begin{array}{ll}
x & y
\end{array}\right] * Q 1\right) *\left[\begin{array}{ll}
x & y
\end{array}\right]\right\}
\end{aligned}
$$

Burada $K$, sınır denkleminin sabit terimidir. $L$ değerleri sınır denkleminin lineer katsayıları iken $Q$ değeri ise sınır denkleminin karesel katsayısıdır.

\section{Bulgular}

Bölgede meydana gelen 95 adet olayın doğal-yapay sarsıntı ayrımı yapılmıştır. İlk olarak göz ile tanımlanmış verilere genlik oranı ve karmaşıklık yöntemleri uygulanmıştır. Bu yöntemlerin kendi içlerinde ayrımlaştırma yapabilmesi için de Lineer ve Karesel Ayrımlaştırma Fonksiyonları'na (LAFKAF) başvurulmuştur. Genlik oranı yöntemi bakıldığında LAF ve KAF için 24 adet patlatma kaydı ayırt edilmiştir. LAF ve KAF için sırasıyla 69 ve 70 adet deprem kaydı ayrımlaştırılırken yine sirasıyla 2 ve 1 tane olay ise sınıflandırılamamıştır (Şekil 3A, 3B). Genlik oranı yöntemine göre hesaplanan LAF Denklem 7'de KAF ise Denklem 8'de verilmiştir. 

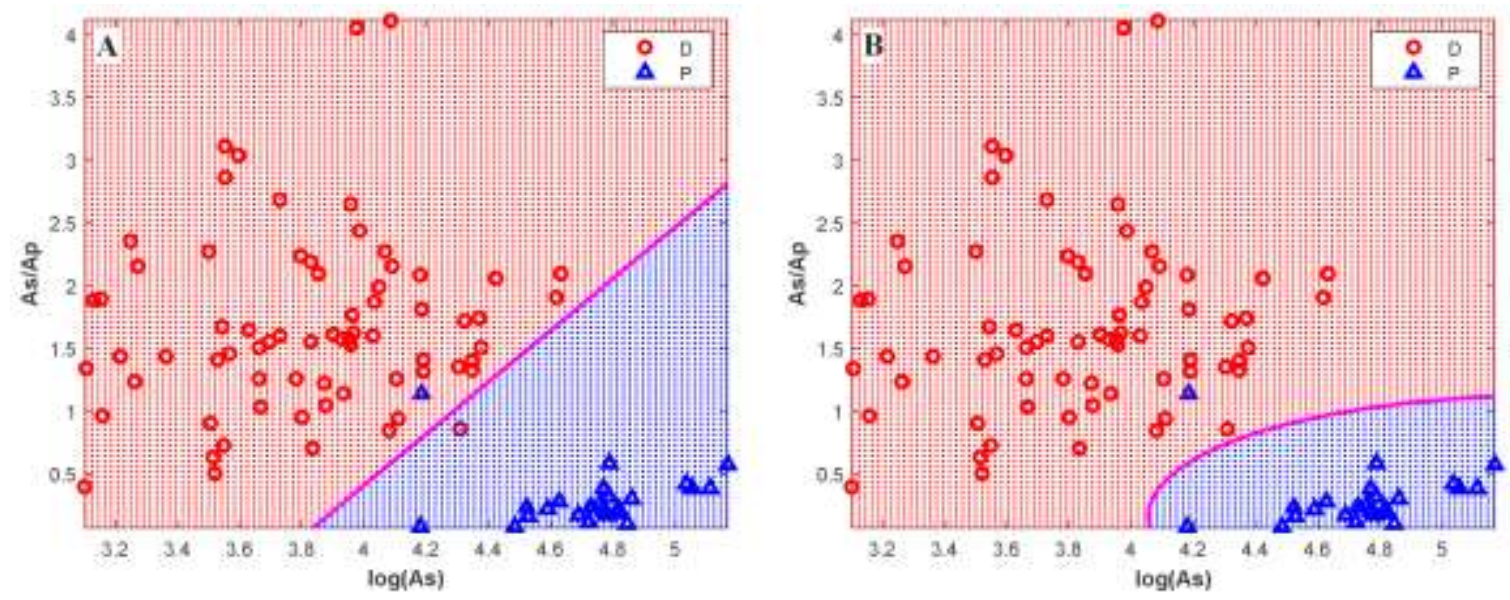

Şekil 3. (A) Genlik oranı yöntemi LAF sonuçları, (B) Genlik oranı yöntemi KAF sonuçları.

$F_{L A F}=31.7124+(-8.3404) * \log A_{s}+(4.0508) * A_{s} / A_{p}$

$F_{K A F}=(143.2941)+\left[\begin{array}{ll}\log A_{s} & A_{s} / A_{p}\end{array}\right] *\left[\begin{array}{c}-56.1535 \\ -6.9694\end{array}\right]+\sum\left\{\left(\left[\begin{array}{ll}\log A_{s} & A_{s} / A_{p}\end{array}\right] *\left[\begin{array}{cc}5.1489 & 0.4909 \\ 0.4909 & 9.2625\end{array}\right]\right) *\left[\begin{array}{ll}\log A_{s} & A_{s} / A_{p}\end{array}\right]\right\}$

Karmaşıklık yöntemi için LAF ve KAF kullanıldığında da ise 24 adet patlatma kaydı ayırt edilmiş̧tir. Fakat bu yöntem için sırasıyla 66 ve 68 tane deprem LAF ve KAF ile ayrımlaştırılırken, yine sırasıyla 5 ve 3 adet olay sınıflandırılamamıştır (Şekil 4A, 4B). Karmaşıklık yöntemi için elde edilen LAF Denklem 9'da ve KAF Denklem 10'da ifade edilmiştir. Tüm sonuçlar Tablo 1'de sayısal olarak verilmiştir.
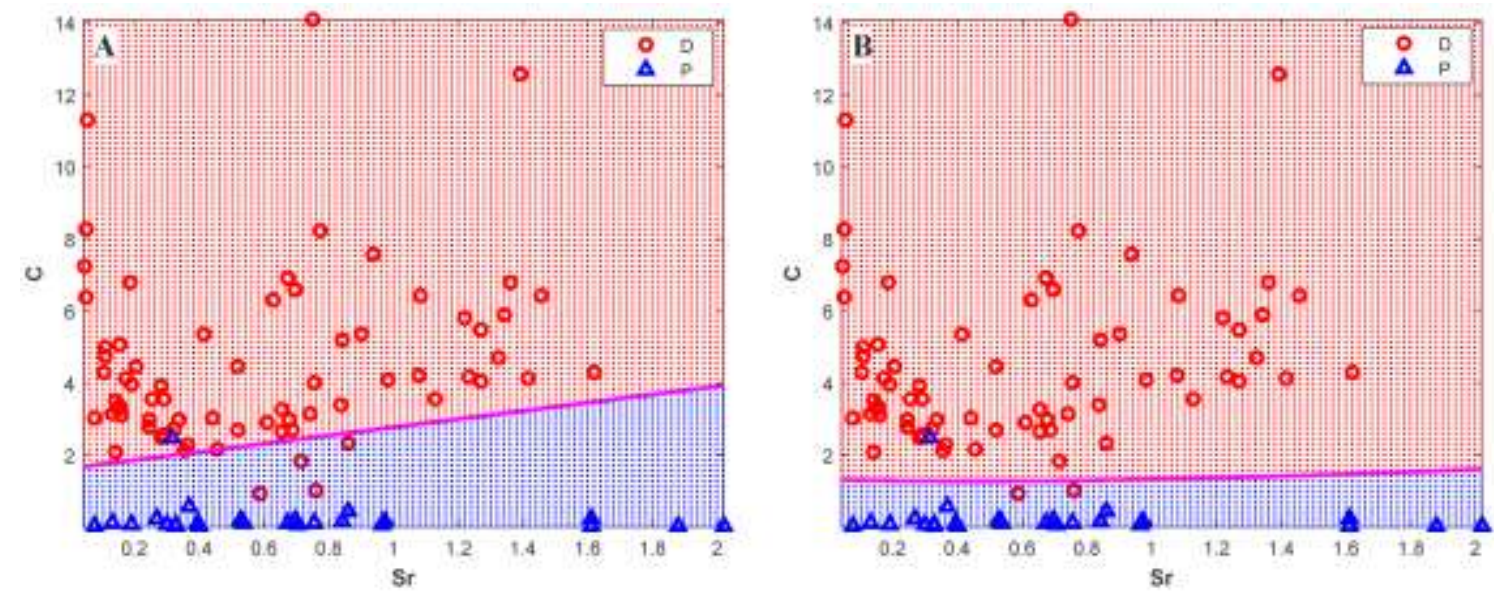

Şekil 4. (A) Karmaşıklık yöntemi LAF sonuçları, (B) Karmaşıklık yöntemi KAF sonuçları.

$F_{L A F}=-1.657+(-1.1549) * \log A_{s}+(1.0139) * A_{S} / A_{p}$

$F_{K A F}=(-2.5424)+\left[\begin{array}{ll}\log A_{s} & A_{s} / A_{p}\end{array}\right] *\left[\begin{array}{l}-0.288 \\ -0.7954\end{array}\right]+\sum\left\{\left(\left[\log A_{s} \quad A_{s} / A_{p}\right] *\left[\begin{array}{cc}-0.9352 & 0.4444 \\ 0.4444 & 2.0587\end{array}\right]\right) *\left[\log A_{s} \quad A_{s} / A_{p}\right]\right\}$

Bu iki yöntem arasında en başarılı çalışan yöntem, genlik oran yöntemi olarak gözükmektedir. Ayrıca istatistiksel yaklaşımlar da kendi içerisinde değerlendirildiğinde KAF sonuçlarının LAF'a göre daha başarılı olduğu tespit edilmiştir. Bu veri setine göre yapılan iki analiz ve istatistiksel yaklaşımlar arasında en uygun olarak genlik oranı yöntemine göre yapılan Karesel Ayrımlaştırma Fonksiyonu'dur. Bu sınıflandırma denklemi ilk yapılan gözleme göre sadece tek bir olayı ayrımlaştıramayarak diğerlerine göre daha sağlıklı sonuçlar vermiştir (\%98.94) (Tablo 1).

SDD analizi ile deprem ve patlatmaların frekans içeriklerinden dolayı ayrımlaştırma daha belirgin bir şekilde yapılabilmektedir (Şekil 5). SDD yöntemi kullanıldığında olayların tamamının birbirinden ayırt edildiği gözlemlenmiştir (\%100) (Tablo 1). Depremlerin ve patlatmaların 06:00-17:00 
(GMT) saat aralığındaki dağılımı Şekil 6'daki histogramda verilmiştir. Buna göre patlatmaların büyük çoğunluğunun 09:00-10:00 (GMT) saatlerinde gerçekleştirildiği tespit edilmiştir. SDD ile kaynak tipi tespit edilen olayların dağılımı da Şekil 7'de gösterilmektedir.

Tablo 1. 95 adet olayın ayrım yöntemlerine ve istatistiksel yaklaşımlara göre sınıflandırma sonuçları.

\begin{tabular}{cccccc}
\hline \multirow{2}{*}{ Yöntem } & $\begin{array}{c}\text { Istatistiksel } \\
\text { Yaklaşım }\end{array}$ & Deprem & Patlatma & $\begin{array}{c}\text { Sinıflandırılamayan } \\
\text { Olay }\end{array}$ & Başarı Oranı (\%) \\
\hline \multirow{2}{*}{ Genlik Oranı } & LAF & 69 & 24 & 2 & 97.89 \\
& KAF & 70 & 24 & 1 & 98.94 \\
Karmaşıklık & LAF & 66 & 24 & 5 & 94.74 \\
SDD & KAF & 68 & 24 & 3 & 96.84 \\
\hline
\end{tabular}
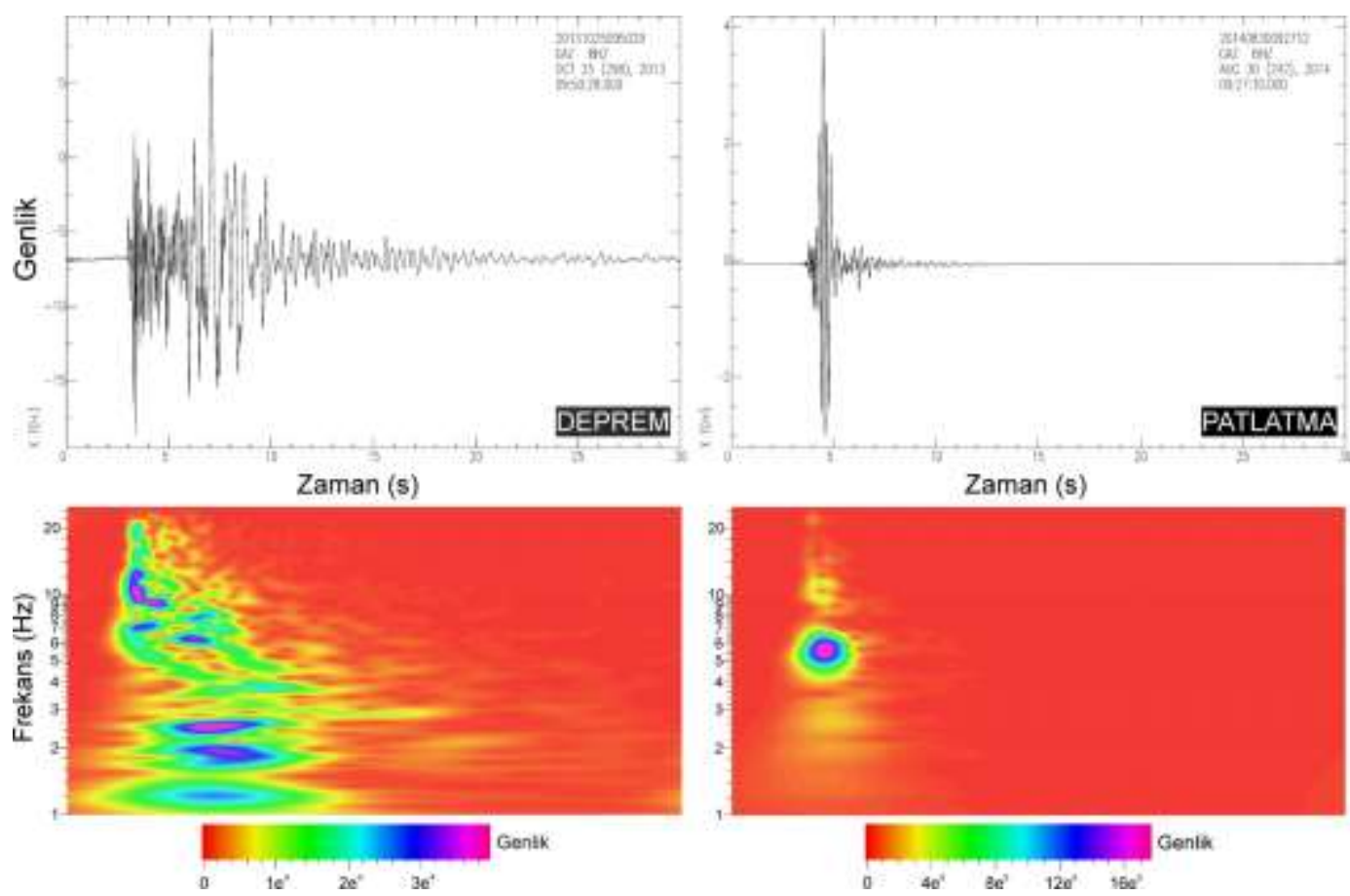

Şekil 5. Sol tarafta 25.10.2013 tarihli 09:50:29 (GMT) saatli bir deprem kaydının GAZ istasyonunun düşey bileşen sismogramı ve ona ait SDD analizi uygulanmış skalogramı. Sağ tarafta 30.08.2014 tarihli 09:27:12 (GMT) saatli bir patlatma kaydının GAZ istasyonunun düşey bileşen sismogramı ve ona ait SDD analizi uygulanmış skalogramı.

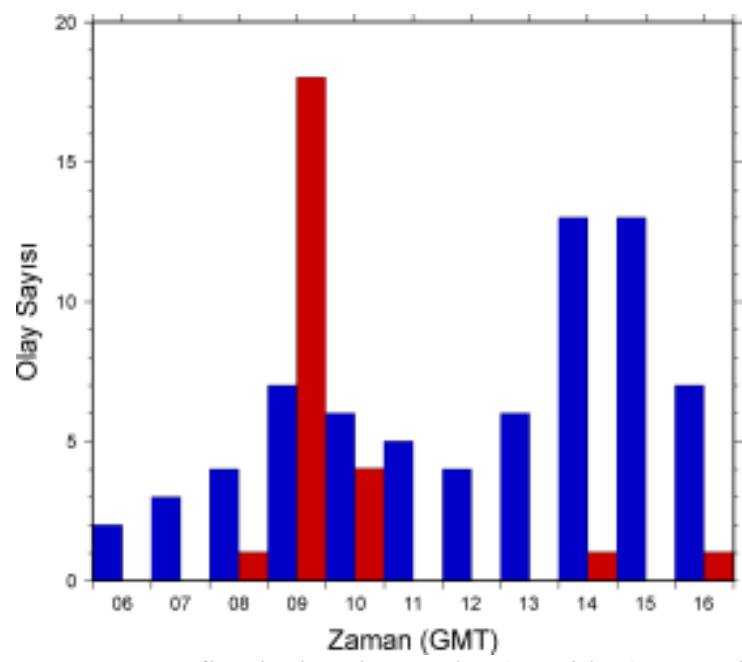

Şekil 6. SDD analizi sonuçlarına göre sınıflandırılan depremler (mavi bar) ve patlatmaların (kırmızı bar) GMT zamanı içerisindeki dağılımları. 


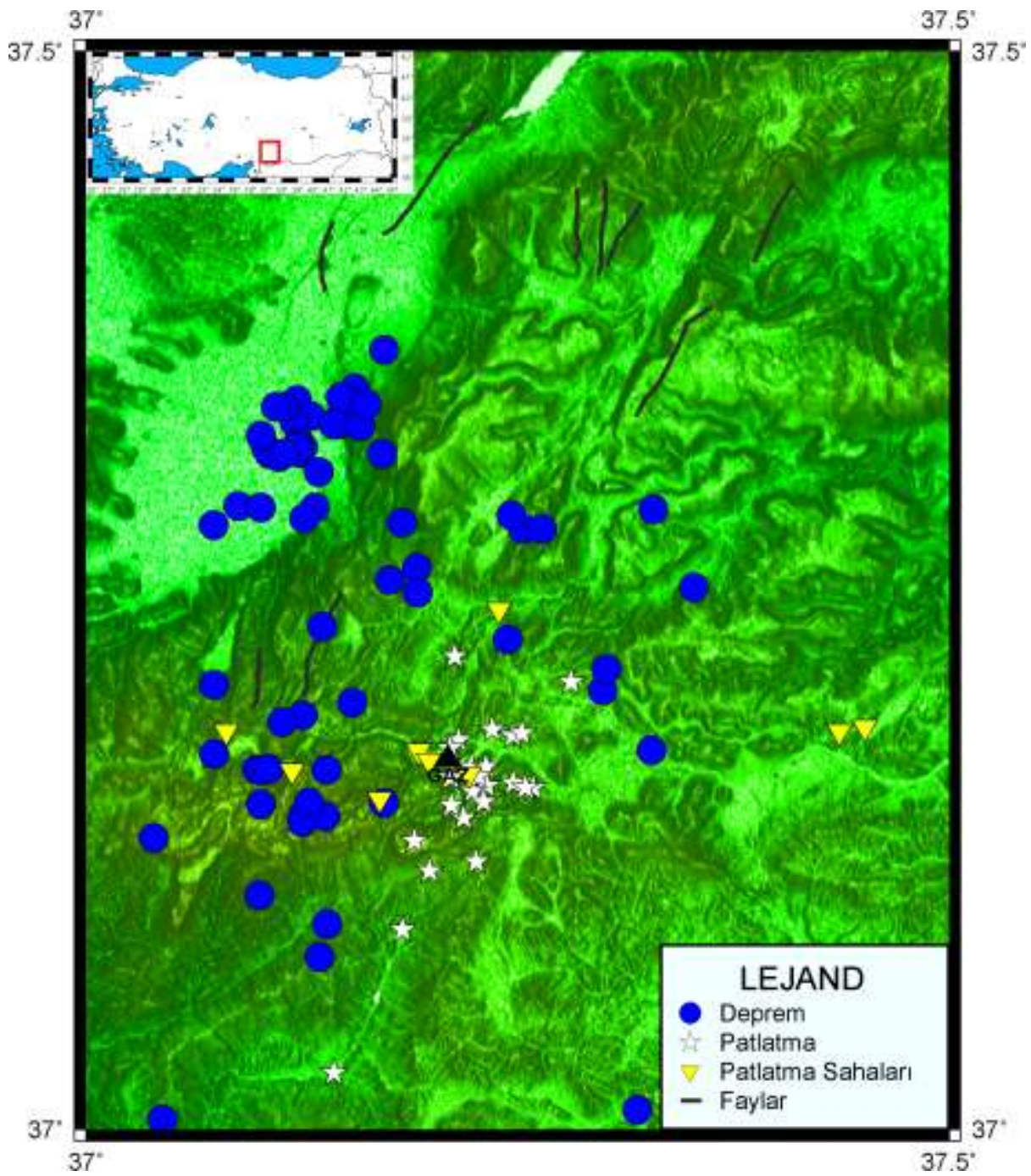

Şekil 7. SDD analizine göre \%100 başarı oranı ile kategorize edilen depremlerin ve taş ocağı patlatmalarının dış merkez dağılımlarını gösterir harita. Faylar, [25]'e dayanılarak çizdirilmiştir.

\section{Sonuçlar ve Tartışma}

$\mathrm{Bu}$ çalışmada Gaziantep-Kahramanmaraş bölgesinde bulunan GAZ sismik istasyonunun verileri kullanılarak doğal-yapay kaynaklı sarsıntıların ayrımlaştırma analizi yapılmıştır. Ocak 2013 ile Nisan 2016 yılları arasında meydana gelmiş $\mathrm{M}_{\mathrm{L}}<3.0$ olan 95 adet veri analiz edilmiştir. 06:00 ile 17:00 (GMT) saatleri arasında, sadece karada oluşan sarsıntıların verileri analiz edilmiştir. Genlik oranı ve karmaşıklık yöntemleri için Lineer ve Karesel Ayrımlaştırma Fonksiyonları kullanılarak sınıflandırma işlemi yapılmıştır. Genlik oranı yöntemi için LAF kullanılarak 69 adet deprem ayırt edilirken KAF kullanılarak 70 tane deprem sınıflandırılmıştır. Karmaşıklık analizinde ise iki istatistiksel yaklaşım sonucunda 24 adet patlatma kaydı ayrımlaştırılmıştır. İki yöntem arasında en iyi sonucun genlik oranı yönteminde kullanılan Karesel Ayrımlaştırma Fonksiyonu'nun sağladığ \% \%98.94 başarı oranı ile gözlenmiştir. Ayrıca tüm verilere SDD analizi de yapılmış ve 70 adet deprem ile 25 adet patlatma kayıtlarının ayrımı \%100 başarı ile gerçekleşmiştir. SDD yöntemi ile bulunan sonuçlar ilk değerlendirme ile de kıyaslandığında tam bir uyum içerisinde olduğu gözlemlenmiştir. Böylece SDD'nin diğer iki yönteme göre daha başarılı ayrım yaptığı tespit edilmiştir. Bu gibi kaynak tipi ayrımlaştırma çalışmalarında sağlıklı sonuçlar elde edebilmek için yöntem sayısının arttırılması ve birçok yöntemin bir arada kullanılması önerilmektedir. Bölge için mevcut sismik katalogların yeniden gözden geçirilmesi ile birlikte doğal-yapay sarsıntı ayrımının yapılması gelecekte yapılacak bilimsel çalışmaların hata paylarının azalmasında önemli katkılar sağlayacaktır. 


\section{Kaynaklar}

[1] Su F., Aki K., Biswas N.N. 1991. Discriminating quarry blasts from earthquakes using coda waves. Bull Seism Soc Am., 81: 162-178.

[2] Aki K. 1995. Discriminating underground explosions from earthquakes using seismic coda waves. University of Southern California Los Angeles Center for Earth Sciences.

[3] Kim W.Y., Aharonian V., Lerner-Lam A.L., Richards P.G. 1997. Discrimination of earthquakes and explosions in southern Russia using regional high-frequency three-component data from the IRIS/JSP Caucasus network. Bull Seism Soc Am., 87: 569-588.

[4] Gitterman Y., Pinsky V., Shapira A. (1998) Spectral classification methods in monitoring small local events by the Israel seismic network. J Seismol., 2: 237-256.

[1] Ataeva G., Gitterman Y., Shapira A. 2017. The ratio between corner frequencies of source spectra of P-and S-waves - a new discriminant between earthquakes and quarry blasts. J Seismol., 21: 209-220.

[5] Yıldırım E., Gülbağ A., Horasan G., Doğan E. 2011. Discrimination of quarry blasts and earthquakes in the vicinity of Istanbul using soft computing techniques. Comput Geosci., 37: 1209-1217.

[6] Yavuz E., Sertçelik F., Livaoğlu H., Woith H., Lühr B-G. 2018. Discrimination of quarry blasts from tectonic events in the Armutlu Peninsula, Turkey. J Seismol., 23: 59-76.

[7] Baumgardt D.R., Young G.B. 1990. Regional seismic waveform discriminants and case-based event identification using regional arrays. Bull Seism Soc Am., 80: 1874-1892.

[8] Wüster J. 1993. Discrimination of chemical explosions and earthquakes in central Europe - a case study. Bull Seism Soc Am., 83: 1184-1212.

[9] Gitterman Y., Shapira A. 1993. Spectral discrimination of underwater explosions. Isr J Earth Sci., 42: 37-44.

[11] Arai N., Yosida Y. 2004. Discrimination by short-period seismograms. International Institute of Seismology and Earthquake Engineering, Building Research Institute (IISEE). Lecture Note, Global Course, Tsukuba, Japan, p. 10.

[12] Roueff A., Chanussot J., Mars J.I., Nguyen M.Q. 2004. Unsupervised separation of seismic waves using the watershed algorithm on time scale images. Geophysical Prospecting, 52 (4): 287-300.

[13] Horasan G., Güney A.B., Küsmezer A., Bekler F., Öğütçü Z., Musaoğlu N. 2009. Contamination of seismicity catalogs by quarry blasts: An example from Istanbul and its vicinity, northwestern Turkey. J Asian Earth Sci., 34: 90-99.

[14] Sertçelik F., Başer O. 2010. Güney Ege Bölgesi’nde yapay ve doğal kaynaklı titreşimlerin ayırt edilmesi. Yerbilimleri, 31: 233-245.

[15] Kekovalı K., Kalafat D., Deniz P. 2012. Spectral discrimination between mining blasts and natural earthquakes: Application to the vicinity of Tunçbilek mining area, Western Turkey. Int J Phys Sci., 7: 5339-5352.

[16] Yılmaz Ş., Bayrak Y., Çınar H. 2013. Discrimination of earthquakes and quarry blasts in the eastern Black Sea region of Turkey. J Seismol., 17: 721-734.

[17] Kuyuk H.S., Yildirim E., Dogan E., Horasan G. 2014. Clustering seismic activities using linear and nonlinear discriminant analysis. J Earth Sci., 25: 140-145.

[18] Sertçelik F., Irmak T.S., Livaoğlu H., Yavuz E., Sertçelik İ., Kurtuluş C. 2016. Spectral analysis of recent Ankara (Turkey) terrorist attacks. 5th Annual International Conference on Geological and Earth Sciences, Full Proceedings, 1: 41-47.

[19] Budakoğlu E., Horasan G. 2018. Classification of seismic events using linear discriminant function (LDF) in the Sakarya region, Turkey. Acta Geophysica, 66 (5): 895-906.

[20] Livaoğlu H., Yavuz E., Sertçelik F., Irmak T.S., Sertçelik İ., Kurtuluş C. 2018. Seismic characterization of the blast occured in Istanbul (Turkey) by the end of 2016. Disaster Science and Engineering, 4 (1): 46-53.

[21] Yavuz E., Livaoğlu H., Irmak T.S., Sertçelik F. 2018. Mersin Akkuyu Nükleer Güç Santrali Civarındaki Sismik Olayların Sınıflandırılması. Türkiye Ulusal Jeodezi ve Jeofizik Birliği Bilimsel Kongresi, 30 Mayıs-2 Haziran 2018, İzmir, Türkiye. 438-441.

[22] McClusky S., Reilinger R., Mahmoud S., Sari D.B., Tealeb A. 2003. GPS constraints on Africa (Nubia) and Arabia plate motions. Geophys J Int., 155: 126-138. 
[23] Reilinger R., McClusky S., Vernant P., Lawrence S., Ergintav S., Cakmak R., Ozener H., Kadirov F., Guliev I., Stepanyan R., Nadariya M., Hahubia G., Mahmoud S., Sakr K., ArRajehi A., Paradissis D., Al-Aydrus A., Prilepin M., Guseva T., Evren E., Dmitrotsa A., Filikov S.V., Gomez F., Al-Ghazzi R., Karam G. 2006. GPS constraints on continental deformation in the AfricaArabia- Eurasia continental collision zone and implications for the dynamics of plate interactions Journal of Geophysical Research: Solid Earth, 111: 9983-9999.

[24] Akbaş B., Akdeniz N., Aksay A., Altun İ., Balcı V., Bilginer E., Bilgiç T., Duru M., Ercan T., Gedik İ., Günay Y., Güven İ.H., Hakyemez H.Y., Konak N., Papak İ., Pehlivan Ş., Sevin M., Şenel M., Tarhan N., Turhan N., Türkecan A., Ulu Ü., Uğuz M.F., Yurtsever A. 2011. Türkiye Jeoloji Haritası Maden Tetkik ve Arama Genel Müdürlüğü Yayını. Ankara, Türkiye.

[25] Emre Ö., Duman T.Y., Özalp S., Elmacı H., Olgun Ş., Şaroğlu F. 2013. 1/1.125.000 Ölçekli Türkiye Diri Fay Haritası, Maden Tetkik ve Arama Genel Müdürlügü Özel Yayınlar Serisi, Ankara, Türkiye.

[26] Başokur A.T. 2007. Spektral analiz ve sayısal süzgeçler. TMMOB Jeofizik Mühendisleri Odası Eğitim Yayınları.

[27] Sertçelik F., Irmak T.S., Livaoğlu H., Yavuz E., Sertçelik İ., Kurtuluş C. 2017. Seismological Analysis of May 12, 2016 Diyarbakir (SE Turkey) Blast, International Conference on Innovative Trends in Engineering, Technology, Computer and Applied Sciences (ITETCAS), Full Proceedings, 2 (7).

[28] Krzanowski W.J. 1988. Principles of multivariate analysis: a user's perspective. Clarendon.

[29] Seber G.A.F. 1984. Multivariate Observations. Hoboken, John Wiley \& Sons, Inc.

[30] MATLAB Release 2015b. The Mathworks, Inc, Natick, Massachusetts, United States. 